\title{
A STUDY ON PREVALENCE OF CAROTID ARTERY STENOSIS IN ACUTE ISCHAEMIC STROKE PATIENTS
}

\author{
Kamatchi Karunanidhi' ${ }^{1}$ Dhurgesa Nanthini Vijaya Sundaram², Murugarajan Singaram ${ }^{3}$
}

${ }^{1}$ Assistant Professor, Department of Medicine, Chengalpattu Medical College, Chengalpattu.

${ }^{2}$ Assistant Professor, Department of Medicine, Chengalpattu Medical College, Chengalpattu.

3Junior Resident, Department of Medicine, Chengalpattu Medical College, Chengalpattu.

\section{ABSTRACT}

\section{BACKGROUND}

Acute ischaemic stroke remains the second most leading cause of death throughout the world and $85 \%$ of strokes are due to infarction. Carotid atherosclerosis remains an important contributor to the ischaemic stroke patients. Internal carotid artery is the commonest site of atherosclerosis and occurs predominantly in diabetic, hypertensive, dyslipidaemic patients.

The aim of our study is to find the prevalence of carotid artery stenosis in acute ischaemic patients and association with risk factors like diabetes mellitus, hypertension, dyslipidaemia.

\section{MATERIALS AND METHODS}

We conducted a cross sectional study of 75 patients admitted in Chengalpattu Medical College over a period of 6 months. Patients who were aged 18-80 years with acute ischaemic stroke less than 2 weeks were selected and included based on inclusion criteria. All patients were systematically analysed including colour Doppler of extracranial arteries and vertebral arteries.

\section{RESULTS}

Statistical analysis was carried out for 75 subjects. Age, presence of diabetes, hypertension, smoking, alcoholism and hyperlipidaemia were analysed in patients with and without carotid stenosis admitted for acute ischaemic stroke. The statistical significance was calculated using Chi- square test. Prevalence of carotid artery stenosis found to be about $46 \%$ among the ischaemic stroke patients enrolled in our study group. The prevalence of carotid artery stenosis rises with old age (66\%), male gender (53\%), smoking (75\%), DM (74\%), HT (74\%) \& Hyperlipidaemia (80\%). DM, HT, Smoking and Hyperlipidaemia act as risk factors for carotid atherosclerosis.

\section{CONCLUSION}

Carotid artery stenosis is one of the common cause of acute ischaemic stroke. So patients with DM, HT, Smoking and Hyperlipidaemia need to have their carotid arteries screened regularly to detect asymptomatic carotid artery stenosis and if present they should strictly control their blood glucose, blood pressure and lipids and start antiplatelet drugs and statins for the purpose of plaque regression and primary prevention of stroke. Surgical intervention like carotid endarterectomy should be done in selected cases for secondary prevention of stroke.

\section{KEYWORDS}

Acute Ischaemic Stroke, Carotid Atherosclerosis, Colour Doppler of Carotid Artery, Carotid Artery Stenosis, Carotid Endarterectomy.

HOW TO CITE THIS ARTICLE: Karunanidhi K, Sundaram DNV, Singaram M. A study on prevalence of carotid artery stenosis in acute ischaemic stroke patients. J. Evolution Med. Dent. Sci. 2016;5(103):7559-7565, DOI: 10.14260/Jemds/2016/1712

\section{BACKGROUND}

Stroke (CVA) still remains the second leading cause of death throughout the world(1) after Coronary Heart Disease. $85 \%$ of stroke cases are due to infarction and $15 \%$ are due to haemorrhage. Carotid atherosclerosis remains an important cause of acute ischaemic stroke.(2)

Carotid atherosclerosis predominantly occurs in patients with risk factors like diabetes mellitus, hypertension, smoking and dyslipidaemia.3,4,5 The internal carotid artery is the commonest site of atherosclerosis next to abdominal aorta followed by the common carotid artery. The extracranial part

Financial or Other, Competing Interest: None.

Submission 19-11-2016, Peer Review 13-12-2016,

Acceptance 19-12-2016, Published 26-12-2016.

Corresponding Author:

Dr. Kamatchi Karunanidhi,

No. 20, F3, SMR Apartments,

$6^{\text {th }}$ Cross Street, Anna Nagar,

Chengalpattu- 603001,

Tamilnadu.

E-mail: kamatchivarshu@gmail.com

DOI: $10.14260 /$ jemds/2016/1712

\section{(c) $($ ) $\ominus$}

of internal carotid artery is the commonest site of atherosclerosis than the intracranial part of internal carotid artery. $6,7,8$

Carotid atherosclerosis will lead to plaque formation and these plaques slowly increase in size and cause significant stenosis. ${ }^{9,10}$ Atherosclerotic plaques disrupt the endothelium and then produce ulcer as the endothelium is breached, platelets adhere to the vessel wall and a haemostatic plug is formed. This platelet nidus initiates the coagulation cascade and thrombus is formed which occludes the vessel lumen.

Thrombus formation on an atherosclerotic plaque will lead to distal embolisation and causes occlusion of blood vessels or a severe stenosis may decrease perfusion, resulting in infarction of the brain tissue.11,12 Atherosclerotic plaques and stenosis can be easily detected by non-invasive (ultrasound) imaging of the carotid arteries which has high sensitivity and specificity in detecting carotid artery stenosis. Patients with carotid artery stenosis are at higher risk of recurrence after a stroke/TIA.13,14

In our study, we attempted to find out the prevalence of carotid artery stenosis in ischaemic stroke patients and irrespective of their risk for recurrence aggressive secondary 
preventive measures can be directed to those patients admitted in Chengalpattu Medical College.

Carotid artery stenosis can be assessed by noninvasive high-resolution B-mode ultrasonography of the carotid arteries. Carotid artery ultrasonography combines B-mode ultrasound image with a Doppler ultrasound assessment of blood flow velocity. These plaques change the blood flow haemodynamics and increases the systolic flow velocity. With this increased systolic flow velocity, the stenosis can be detected and its severity can be assessed, and this can be helpful for further management of ischaemic stroke patients with carotid artery stenosis.

\section{Aims and Objectives}

1. To find out the prevalence of carotid artery stenosis in acute ischaemic stroke patients.

2. To find out the association between carotid artery stenosis and factors such as diabetes mellitus, hypertension, hyperlipidaemia, smoking and age.

\section{MATERIALS AND METHODS}

It is a cross sectional study of 75 patients admitted in the Chengalpattu Medical College during the period Jan. 2016 to June 2016. Inclusion criteria were all patients of both sexes between 18 to 80 years with stroke of less than 2 weeks' duration with CT brain showing acute infarct admitted in Department of Medicine, Chengalpattu Medical College. Those patients with stroke more than 2 weeks, haemorrhagic stroke, malignancy, HIV, tuberculosis, metabolic or haemodynamically unstable patients, any other chronic serious illness and those who have not given consent for the study are excluded from this study. All the patients were asked about detailed medical history and examined systematically by clinical examination, investigations like CBC, RFT, Electrolytes, LFT, Fasting Blood sugar, Fasting Lipid profile, Urine Analysis, ECG, Echocardiography, CT Brain plain study, Colour Doppler of Extracranial arteries and Vertebral arteries. Systolic and diastolic velocity of blood flow, carotid intimamedia thickness, presence of atheromatous plaque and thrombus was looked for and then the percentage of stenosis of the affected arteries were calculated with coordination from our Radiology Department.

\section{Observation and Analysis}

Statistical analysis was carried out for 75 subjects. Age, presence of diabetes, hypertension, smoking, alcoholism and hyperlipidaemia were analysed in patients with and without carotid stenosis admitted for acute ischaemic stroke. The statistical significance was calculated using Chi- square test.

\section{RESULTS}

We included 75 patients with acute ischaemic stroke in our study and all of them had a carotid Doppler done.

\begin{tabular}{|c|c|c|c|}
\hline $\begin{array}{c}\text { No. of } \\
\text { Patients in } \\
\text { whom } \\
\text { Carotid } \\
\text { Doppler was } \\
\text { Done }\end{array}$ & $\begin{array}{c}\text { Patients } \\
\text { with } \\
\text { Carotid } \\
\text { Stenosis }\end{array}$ & Percentage & $\begin{array}{c}\text { Patients } \\
\text { without } \\
\text { Carotid } \\
\text { Stenosis }\end{array}$ \\
\hline 75 & 35 & $46 \%$ & 40 \\
\hline \multicolumn{2}{|c|}{ Table 1. Prevalence of Carotid Stenosis in Acute } \\
Ischaemic Stroke Patients \\
\hline
\end{tabular}

\begin{tabular}{|c|c|c|}
\hline Characteristics & Present & Absent \\
\hline Diabetes & 27 & 48 \\
\hline Hypertension & 39 & 36 \\
\hline Smoking & 37 & 38 \\
\hline Increased total cholesterol & 41 & 34 \\
\hline Increased LDL & 31 & 44 \\
\hline Decreased HDL & 16 & 59 \\
\hline Increased TGL & 40 & 35 \\
\hline \multicolumn{2}{|c}{ Table 2. Patient Characteristics } \\
\hline
\end{tabular}

\begin{tabular}{|c|c|c|c|}
\hline Age Group & Total & Carotid Stenosis & No Stenosis \\
\hline$<50$ & 31 & 9 & 22 \\
\hline $50-59$ & 32 & 18 & 14 \\
\hline$>60$ & 12 & 8 & 4 \\
\hline \multicolumn{4}{|c|}{ Table 3. Age Distribution of Carotid Stenosis in Stroke Patients } \\
\hline
\end{tabular}

\begin{tabular}{|c|c|}
\hline Age & Percentage of Patients \\
\hline$<50$ & $29 \%$ \\
\hline $50-59$ & $56 \%$ \\
\hline$>60$ & $66 \%$ \\
\hline \multicolumn{2}{|c|}{ Table 4. Percentage of Patients with Carotid Stenosis in } \\
Different Age Groups \\
\hline
\end{tabular}

$\mathrm{P}=0.03046$

It was found that percentage of patients with carotid stenosis was increasing with increase in age and there was a statistically significant association between age and carotid stenosis $(\mathrm{p}<0.05)$.

In our study out of 20 young stroke patients between 1545 years, 5 patients had carotid stenosis. The prevalence of stenosis was about $25 \%$ in those patients.

\begin{tabular}{|c|c|c|c|}
\hline Sex & Total & Stenosis & No Stenosis \\
\hline Male & 60 & 32 & 28 \\
\hline Female & 15 & 3 & 12 \\
\hline Total & $\mathbf{7 5}$ & $\mathbf{3 5}$ & $\mathbf{4 0}$ \\
\hline \multicolumn{4}{|c|}{ Table 5. Sex Distribution of Carotid Stenosis } \\
\hline
\end{tabular}

$\mathrm{P}=0.02064$

\begin{tabular}{|c|c|}
\hline Sex & Percentage of Patients \\
\hline Male & $53 \%$ \\
\hline Female & $20 \%$ \\
\hline \multicolumn{2}{|c|}{ Table 6. Percentage of Male and Female Patients with } \\
Carotid Stenosis
\end{tabular}

$\mathrm{P}<0.001$

It was found that more male patients had carotid stenosis than female patients and it was statistically significant.

Risk Factor Analysis in Carotid Stenosis Patients

\begin{tabular}{|c|c|c|c|}
\hline & Total & Stenosis & No Stenosis \\
\hline DM & 27 & 20 & 7 \\
\hline Non-DM & 48 & 15 & 33 \\
\hline Total & $\mathbf{7 5}$ & $\mathbf{3 5}$ & $\mathbf{4 0}$ \\
\hline \multicolumn{4}{|c|}{ Table 7. Correlation between Diabetes Mellitus and } \\
Carotid Stenosis \\
\hline
\end{tabular}

$\mathrm{P}=0.00036$

There was a correlation between DM and carotid stenosis. More DM patients had carotid stenosis than Non - DM patients and it was statistically significant. 


\begin{tabular}{|c|c|c|c|}
\hline & Total & Stenosis & No Stenosis \\
\hline Hypertension & 39 & 29 & 10 \\
\hline Normal & 36 & 6 & 30 \\
\hline Total & $\mathbf{7 5}$ & $\mathbf{3 5}$ & $\mathbf{4 0}$ \\
\hline \multicolumn{4}{|c|}{ Table 8. Correlation between Hypertension and Carotid } \\
Stenosis \\
\hline
\end{tabular}

$\mathrm{P}<0.001$. Prevalence of carotid stenosis was more in hypertensive patients than in normotensive patients and it was statistically significant.

\begin{tabular}{|c|c|c|c|}
\hline & Total & Stenosis & No Stenosis \\
\hline Smokers & 37 & 28 & 9 \\
\hline Non-smokers & 38 & 7 & 31 \\
\hline Total & $\mathbf{7 5}$ & $\mathbf{3 5}$ & $\mathbf{4 0}$ \\
\hline Table 9. Correlation between Smoking and Carotid \\
Stenosis \\
\hline
\end{tabular}

$\mathrm{P}<0.001$

Prevalence of carotid stenosis was more in smokers than in non-smokers and it was statistically significant.

\begin{tabular}{|c|c|c|c|}
\hline & Total & Stenosis & $\begin{array}{c}\text { No } \\
\text { Stenosis }\end{array}$ \\
\hline $\begin{array}{c}\text { Cholesterol (>200 } \\
\mathrm{mg} / \mathrm{dL})\end{array}$ & 41 & 25 & 16 \\
\hline $\begin{array}{c}\text { Cholesterol }(<200 \\
\mathrm{mg} / \mathrm{dL})\end{array}$ & 34 & 10 & 24 \\
\hline Total & 75 & 35 & 40 \\
\hline \multicolumn{4}{|c|}{$\begin{array}{c}\text { Table 10. Correlation between Patients with High } \\
\text { Cholesterol and Carotid Stenosis }\end{array}$} \\
\hline
\end{tabular}

$\mathrm{P}=0.006$

Prevalence of carotid stenosis was more in patients with high cholesterol than in patients with normal cholesterol and it was statistically significant.

\begin{tabular}{|c|c|c|c|}
\hline & Total & Stenosis & No Stenosis \\
\hline TGL $>150$ & 41 & 28 & 12 \\
\hline TGL $<150$ & 34 & 7 & 28 \\
\hline Total & $\mathbf{7 5}$ & $\mathbf{3 5}$ & $\mathbf{4 0}$ \\
\hline \multicolumn{4}{|r|}{ Table 11. Carotid Stenosis in Patients } \\
with High TGL \\
\hline
\end{tabular}

\section{$\mathrm{P}<0.001$}

Prevalence of carotid stenosis was more in patients with high TGL than in patients with normal TGL and it was statistically significant.

\begin{tabular}{|c|c|c|c|}
\hline & Total & Stenosis & No Stenosis \\
\hline $\mathrm{HDL}>40$ & 59 & 22 & 37 \\
\hline $\mathrm{HDL}<40$ & 16 & 13 & 3 \\
\hline Total & $\mathbf{7 5}$ & $\mathbf{3 5}$ & $\mathbf{4 0}$ \\
\hline \multicolumn{4}{|c|}{$\begin{array}{c}\text { Table 12. Prevalence of Carotid } \\
\text { Stenosis in Low HDL Patients }\end{array}$}
\end{tabular}

$\mathrm{P}=0.002$

Prevalence of carotid stenosis was more in patients with Low HDL than in patients with normal HDL and it was statistically significant.

\begin{tabular}{|c|c|c|c|}
\hline & Total & Stenosis & No Stenosis \\
\hline LDL $>130$ & 31 & 25 & 6 \\
\hline LDL $<130$ & 44 & 10 & 34 \\
\hline Total & 75 & 35 & 40 \\
\hline \multicolumn{4}{|c|}{ Table 13. Carotid Stenosis in Patients } \\
with High LDL \\
\hline
\end{tabular}

\section{$\mathrm{P}<0.001$}

Prevalence of carotid stenosis was more in patients with high LDL than in patients with normal LDL and it was statistically significant.

\begin{tabular}{|c|c|c|}
\hline Degree of Stenosis & $\begin{array}{l}\text { No. of } \\
\text { Cases }\end{array}$ & Percentage \\
\hline Mild stenosis $(<50 \%)$ & 13 & $17 \%$ \\
\hline Moderate stenosis (50-69\%) & 12 & $16 \%$ \\
\hline $\begin{array}{l}\text { Severe or Significant stenosis } \\
\qquad(>70 \%)\end{array}$ & 10 & $13 \%$ \\
\hline No stenosis & 40 & $54 \%$ \\
\hline \multicolumn{3}{|c|}{$\begin{array}{c}\text { Table 14. Degree of Carotid Stenosis in Ischaemic Stroke } \\
\text { Patients }\end{array}$} \\
\hline
\end{tabular}

The prevalence of mild stenosis and moderate stenosis were more than severe stenosis. In our study, 2 cases with server stenosis had carotid bruit.

\begin{tabular}{|c|c|}
\hline Right & Left \\
\hline 17 & 18 \\
\hline \multicolumn{2}{|c|}{ Table 15. Carotid stenosis on Right side and Left side } \\
\hline
\end{tabular}

$\mathrm{P}=0.8658$

There was no particular side preponderance of carotid stenosis and it was more or less equal on both sides and there was no statistical significance between two sides.

\begin{tabular}{|c|c|c|c|}
\hline Side & ICA & CCA & Total \\
\hline Right & 12 & 5 & 17 \\
\hline Left & 13 & 5 & 18 \\
\hline Total & $\mathbf{2 5}$ & $\mathbf{1 0}$ & $\mathbf{3 5}$ \\
\hline \multicolumn{4}{|c|}{ Table 16. Site of Carotid Stenosis } \\
\hline
\end{tabular}

\section{$\mathrm{P}=0.914$}

It was found that carotid stenosis was more in internal carotid arteries both on Right and Left side than common carotid arteries, but it was not statistically significant.

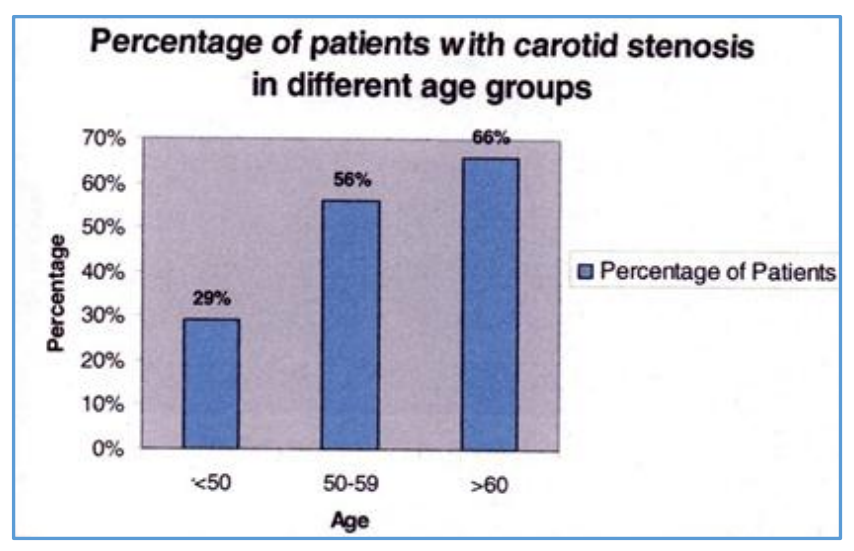

Figure 1 


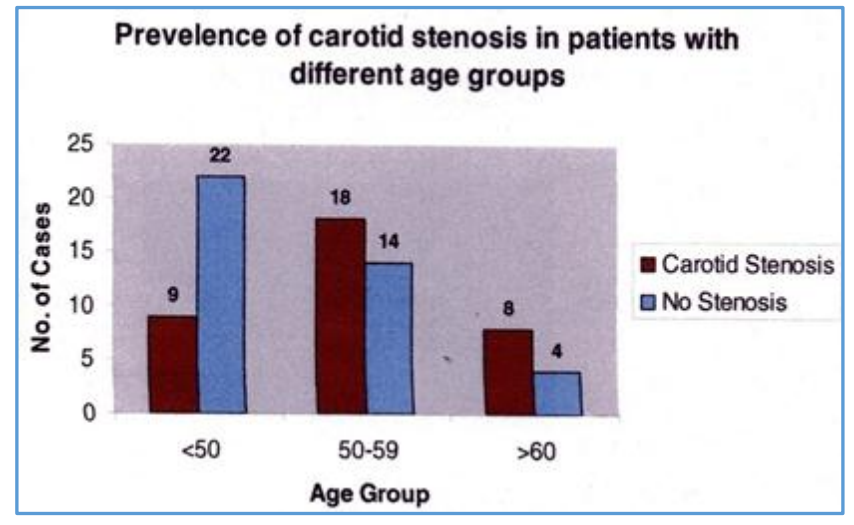

Figure 2

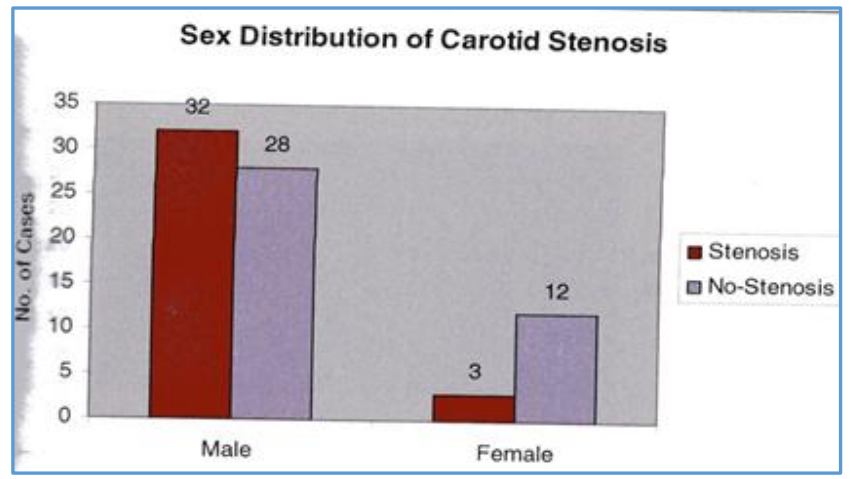

Figure 3

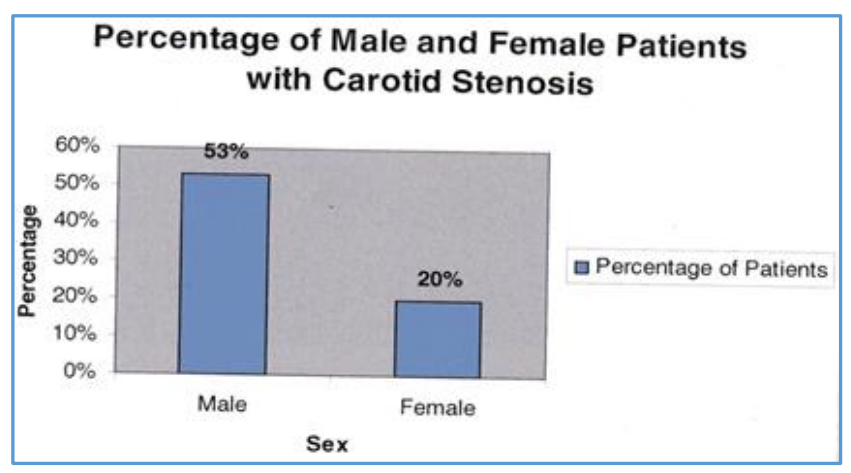

Figure 4

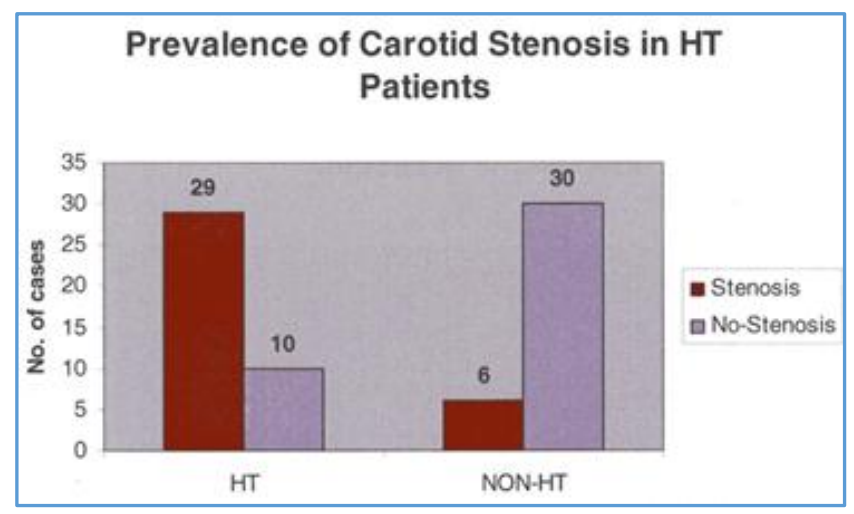

Figure 5

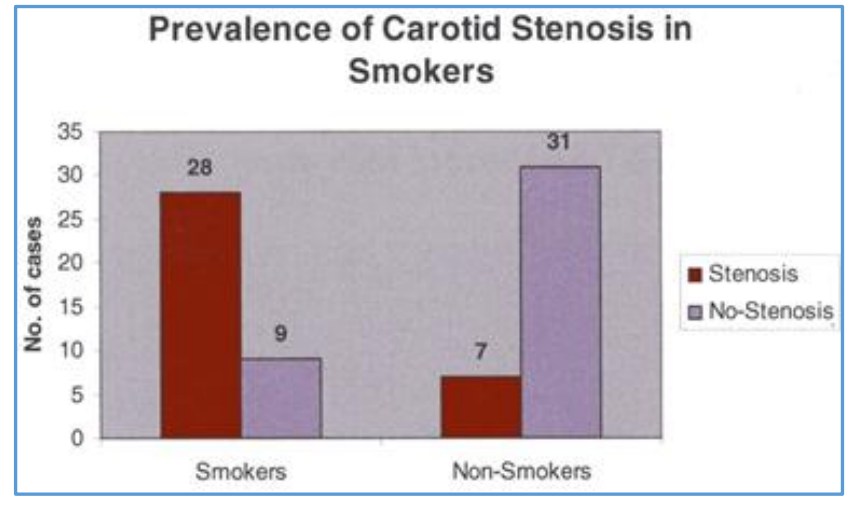

Figure 6

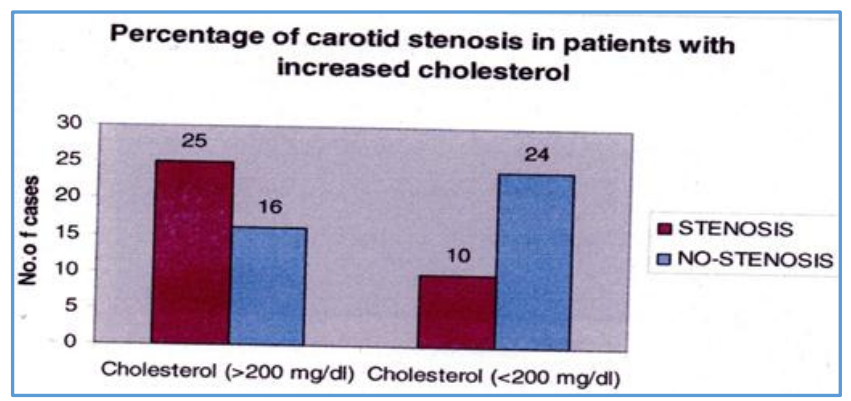

Figure 7

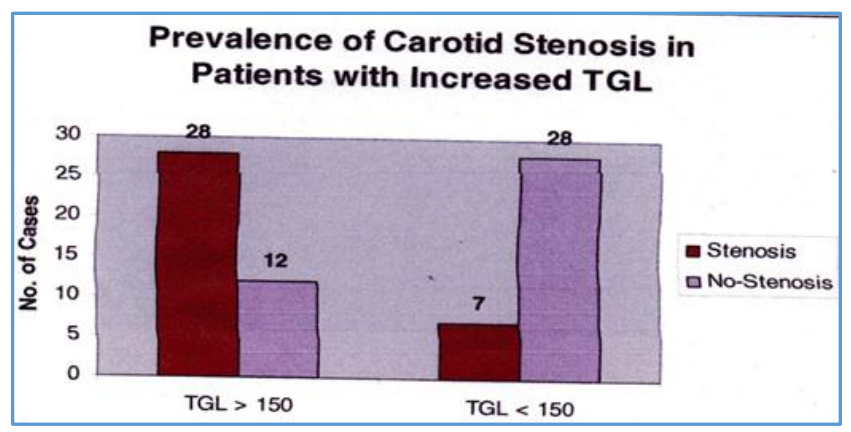

Figure 8

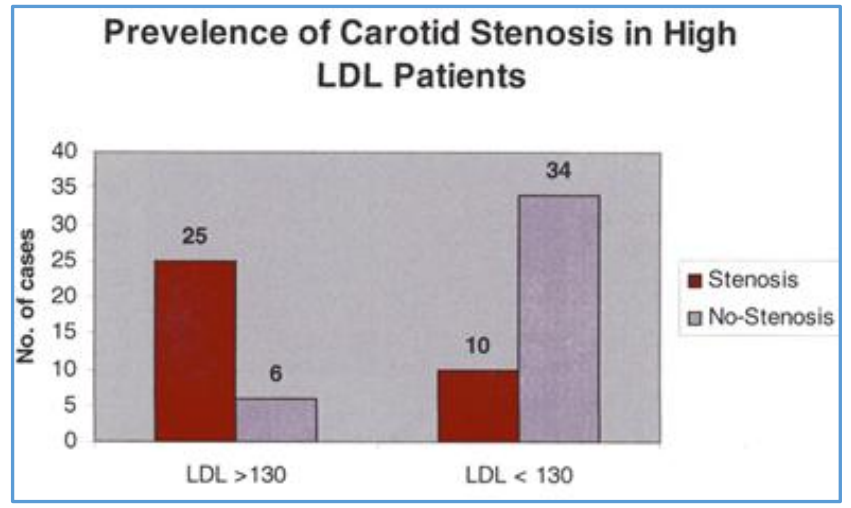

Figure 9 


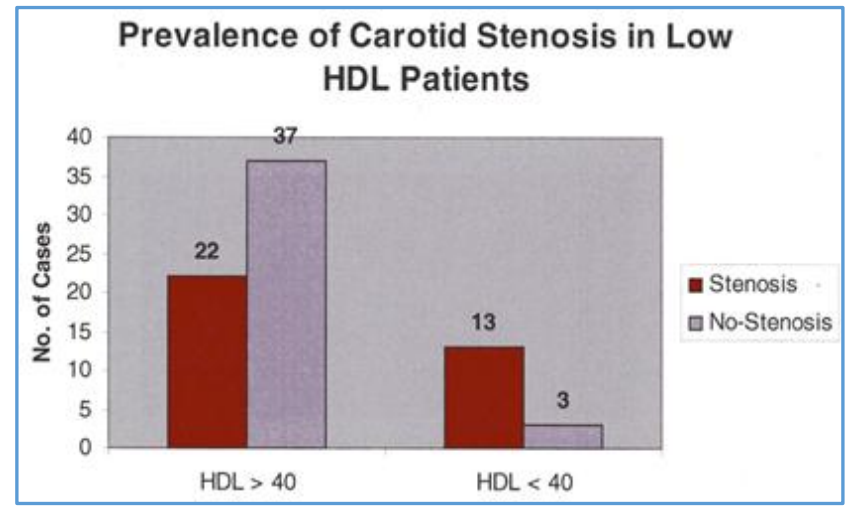

Figure 10

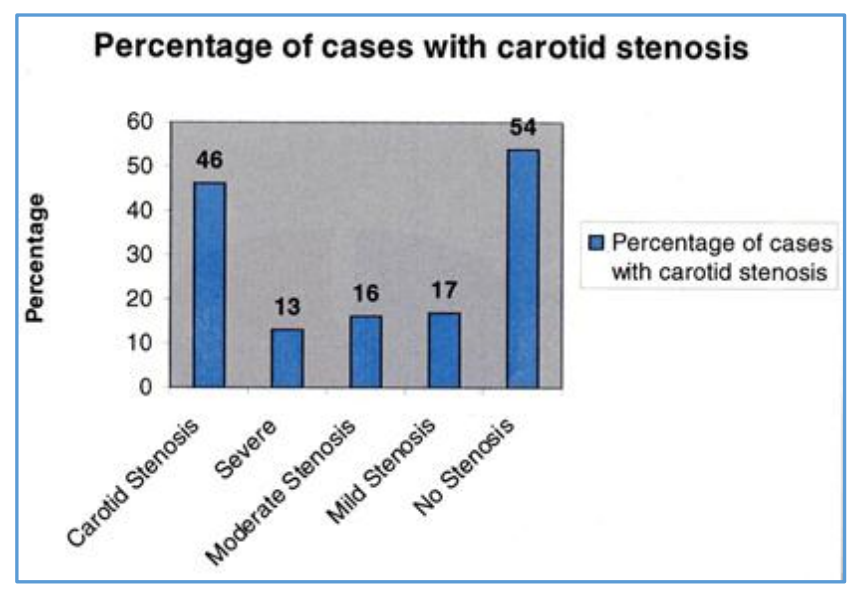

Figure 11

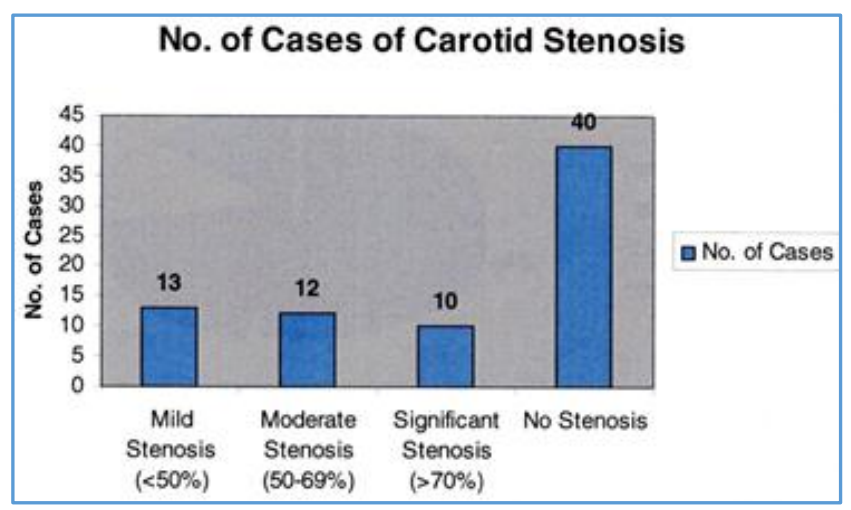

Figure 12

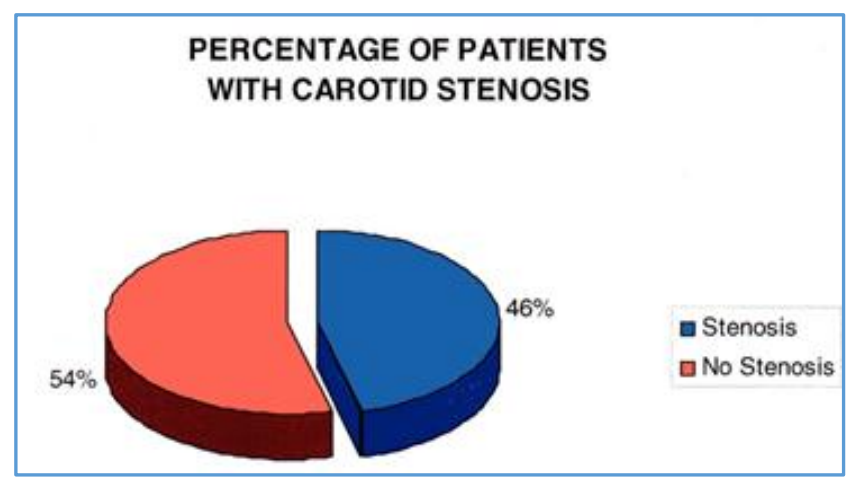

Figure 13

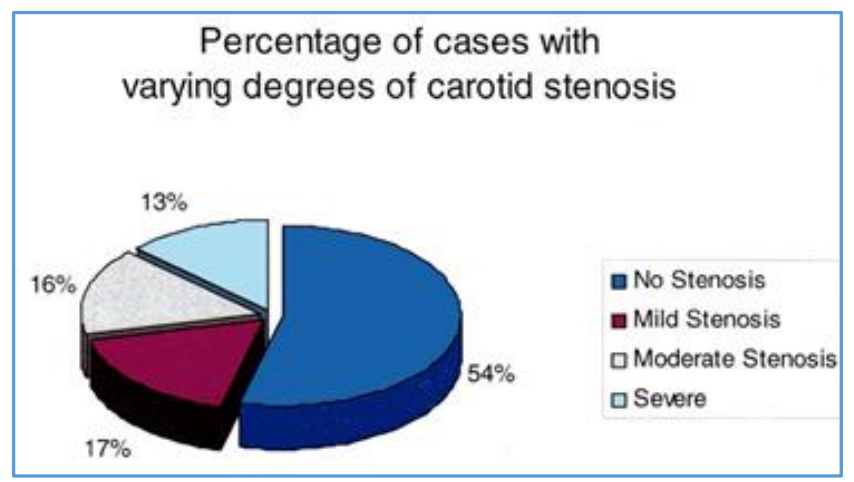

Figure 14

\section{DISCUSSION}

Prevalence of carotid stenosis in acute ischaemic stroke patients is about $46 \%$ in our study, which is consistent with other studies that was about $43 \%$ in ischaemic stroke patients.

The prevalence of patients with significant stenosis $(>70 \%)$ was about $13 \%$ which is associated with increased recurrence of stroke. The prevalence of significant stenosis in studies conducted in western population is about $14 \%$ and $21 \%$. This variation could be explained due to racial difference.(14) Extracranial carotid artery stenosis is more common in whites than black and men than women.(14) The prevalence of significant stenosis in a study conducted by M.M. Singh et al was about $32 \%$.

The prevalence of moderate stenosis was about $16 \%$, mild stenosis was $17 \%$ and $54 \%$ of stroke patients had no carotid stenosis in our study. Asymptomatic carotid stenosis prevalence was found to be $>50 \%$ in a study conducted in asymptomatic carotid stenosis patients by P.P. Mineva.(15)

\section{Analysis of Age with Carotid Stenosis}

In our study, the percentage of patients with carotid stenosis was increasing with increase in age.(15) The prevalence in patients $<50$ years, 50-69 years, $>60$ years was about $29 \%$, $56 \%, 66 \%$ respectively. A study conducted by K. Rajamani et al clearly showed the increasing incidence of carotid stenosis with older age in African American Men. Carotid stenosis due to atherosclerosis increases with age. The risk of carotid atherosclerosis increases after the mean age of 45 years.

\section{Analysis of Sex with Carotid Stenosis}

We found that male/female ratio for the carotid stenosis has increased i.e. the prevalence of carotid stenosis was more in males (53\%) than females (20\%) which was consistent with studies conducted by Jacob et al. It is also shown by Ralph et al that carotid stenosis was more common in males (43\%) than females.

\section{Analysis of Risk Factors for Carotid Atherosclerosis}

\section{Diabetes Mellitus and Carotid Stenosis}

In our study, carotid artery stenosis was more prevalent in diabetics (74\%) than in non-diabetics (31\%) and it was statistically significant $(\mathrm{P}<0.05)$. K. Rajamani et al have shown in their study that carotid stenosis was more common in diabetics (22\%) which is consistent with our study.

\section{Hypertension and Carotid Stenosis}

In our study, we found that Hypertension was the major risk factor for carotid stenosis and the prevalence of carotid 
stenosis found to be (74\%) in systemic hypertensive patients than in normotensive (16\%) patients which was also consistent with studies done by Duncan et al, Sutton et al. In their study, it was found that asymptomatic carotid stenosis was found in $25 \%$ of adults with systemic hypertension than those without systemic hypertension. Systemic hypertension accelerates carotid stenosis. The predictors of carotid stenosis were systolic $\mathrm{BP}>160 \mathrm{mmHg}$ and in isolated systolic hypertension patients when diastolic BP was $<75 \mathrm{mmHg}$ there was a strong correlation with carotid stenosis.

\section{Smoking and Carotid Stenosis- The Risk Analysis}

In our study, we found that the smoking acts as a significant risk factor for carotid artery stenosis. The smokers (75\%) had carotid artery stenosis significantly than non-smokers (18\%), which is also shown by H.R. Muller et al. Smoking is a major risk factor for carotid stenosis.

\section{Hyperlipidaemia and Carotid Stenosis- The Risk Analysis}

In our study, among the patients with increased cholesterol $(>200 \mathrm{mg} / \mathrm{dL}$ ) the prevalence of carotid artery stenosis was $61 \%$, the prevalence of carotid artery stenosis with increased TGL ( $>150 \mathrm{mg} / \mathrm{dL}$ ) was $70 \%$ and increased LDL ( $>130 \mathrm{mg} / \mathrm{dL})$ was $80 \%$. The prevalence of carotid artery stenosis in patients with normal cholesterol $(<200 \mathrm{mg} / \mathrm{dL})$ was $29 \%$, normal TGL $(<150 \mathrm{mg} / \mathrm{dL}$ ) was $20 \%$, normal HDL ( $>40 \mathrm{mg} / \mathrm{dL}$ ) and LDL $(<130 \mathrm{mg} / \mathrm{dL}$ ) were found to be $37 \%$, and $22 \%$ respectively.

Prevalence of carotid stenosis, just like coronary atherosclerotic disease, increased with Hypercholesterolaemia $(>200 \mathrm{mg} / \mathrm{dL})$ and Increased LDL $(>130 \mathrm{mg} / \mathrm{dL})$ and decreased HDL $(<40 \mathrm{mg} / \mathrm{dL}) \cdot{ }^{16,17,11}$ They are associated with extracranial large vessel atherosclerosis and also coronary atherosclerosis leads to increase in IMT and plaque formation and stenosis. Extracranial carotid atherosclerosis is associated with major brain vessel occlusion leading to infarction of brain tissue.(17)

\section{Site and Carotid Stenosis- Analysis}

In our study, carotid artery stenosis was found predominantly at the bifurcation of CCA, and the origin of ICA. Carotid artery stenosis was found equal on both sides and was more on ICA than CCA. ICA stenosis was found in $71 \%$ of patients and CCA stenosis was found in $28 \%$ of patients.

We have found that age, male gender, smoking, DM, HT \& Hyperlipidaemia are associated with increased rate of carotid stenosis. In our study, every patient with carotid artery stenosis had one or the other risk factor for Carotid atherosclerosis. In other words, there were no patients with carotid artery stenosis without any risk factor in our study. Hence, asymptomatic patients with these risk factors should be screened for carotid stenosis to prevent stroke.

\section{CONCLUSION}

Carotid artery stenosis is one of the common cause of acute ischaemic stroke.

Prevalence of carotid artery stenosis was found to be about $46 \%$ among the ischaemic stroke patients enrolled in our study group.

The prevalence of carotid artery stenosis rose with older age, male gender, smoking, DM, HT \& Hyperlipidaemia. DM, HT, Smoking and Hyperlipidaemia act as risk factors for carotid atherosclerosis. So patients with DM, HT, Smoking and
Hyperlipidaemia need to have their carotid arteries screened regularly to detect asymptomatic carotid artery stenosis and if present they should strictly control their blood glucose, blood pressure and lipids and start antiplatelet drugs and statins for the purpose of plaque regression and primary prevention of stroke. Patients with stroke who have carotid artery stenosis (symptomatic/significant carotid stenosis) are prone to recurrence of stroke. It is better to advise them to control the risk factors for carotid atherosclerosis/stenosis and should be started on medications like antiplatelet drugs and statins. ${ }^{18,19}$ Surgical intervention like carotid endarterectomy should be done in selected cases for secondary prevention of stroke. ${ }^{20}$ It can be concluded that Doppler sonography of the carotid arteries in high risk individuals could therefore have profound diagnostic and therapeutic implication (as it is a simple noninvasive screening procedure) in predicting and preventing a potentially fatal and devastating stroke.

\author{
Abbreviations \\ TIA: Transient Ischaemic Attack. \\ ICH: Intra Cranial Haemorrhage. \\ SAH: Sub Arachnoid Haemorrhage. \\ ASD: Atrial Septal Defect. \\ DIC: Disseminated Intravascular Coagulation. \\ ICA: Internal Carotid Artery. \\ CCA: Common Carotid Artery. \\ ECA: External Carotid Artery. \\ LDL: Low Density Lipoprotein. \\ HDL: High Density Lipoprotein. \\ OCP: Oral Contraceptive Pills. \\ DM: Diabetes Mellitus. \\ HT: Hypertension. \\ LVH: Left Ventricular Hypertrophy. \\ SEC: Spontaneous Echo Contract. \\ LVEF: Left Ventricular Ejection Fraction. \\ CT: Computed Tomography. \\ USG: Ultra Sonography. \\ FBS: Fasting Blood Sugar.
}

\section{REFERENCES}

1. Murray CJL, Lopez AD. Mortality by cause for eight regions of world: global burden of disease study. LANCET 1997;349(9061):1269-76.

2. Sacco RL, Ellenberg JH, Mohr JP, et al. Infarcts of undetermined causes: the NINCDS stroke data bank. Ann Neurology 1989;25(4):382-90.

3. Park K. Parks textbook of preventive and social medicine. $20^{\text {th }}$ edn. Jabalpur Banarsidas Bhanot publishers 1994.

4. Prasad K. Recent concepts in stroke. In: Bansal BC, Agarwal AK, (eds). Epidemiology of cerebrovascular disease in India, Mumbai: Indian college of Physicians 1999:11-9.

5. McMohan S. Introduction the global burden of stroke. In: Chalmess J (edr). Clinicians manual of blood pressure and stroke prevention science press, London 2002.

6. Baker $\mathrm{AB}$, Iannone $\mathrm{A}$. Cerebrovascular disease the large arteries of circle of wills. Neurology 1959;9(5):321-2.

7. Fisher M, Francis R, Gore I, et al. Atherosclerosis of carotid and vertebral arteries - extra and intra cranial arteries. Neuropathol Exp Neurol 1965;24:455-76.

8. Timsit SG, Sacco RL, Mohr JP, et al. Early clinical differentiation of cerebral infarction from severe 
atherosclerotic stenosis and cardioembolism. Stroke 1992;23(4):486-91.

9. Fisher M, Sacoolidge JC, Taylor CR. Patterns of fibrin deposits in carotid artery plaques. Angiology 1987;38(5):393-9.

10. Schmid-Schonbein H, Perktold K. Physical factors in the pathogenesis of atheroma formation. Springer 1995:185213.

11. Collins RC, Dubkin BH, Choi DW. Selective vulnerability of brain: new insights into pathophysiology of stroke. Ann Internal Medicine 1989;110:992-1000.

12. Choi DW. Excitotoxicity and Stroke. In: Caplan LR, (edr) Brain ischemia, basic concepts and clinical relevance. London: Springer 1995:29-36.

13. Kasper DL, Fauci AS, Hauser S. Harrison's manual of medicine. 19th edn. McGraw Hill Professional 2016:p 1248.

14. Hackam DG, Anand SS. Emerging risk factors for atherosclerotic vascular disease. JAMA 2003;290(7):93240 .
15. Silvestrini M, Vernieri F, Pasqualetti $P$, et al. Impaired cerebral vasoreactivity and risk of stroke in patients with asymptomatic carotid stenosis. JAMA 2000;283(16):21227.

16. Ropper $\mathrm{AH}$, Brown RH. Adam and victors principles of neurology. $8^{\text {th }}$ edn. McGraw-Hill Companies Inc, New York 2005.

17. Garcia JH, Anderson ML. Pathophysiology of cerebral ischemia. Crit Rev Neurobiol 1989;4(4):303-24

18. Weiss HJ. Platelet physiology and abnormalities of platelet function (second of two parts). $\mathrm{N}$ Engl J Med 1975;293(12):580-8.

19. Ashby B, Daniel JC, Smith JB. Mechanism of platelet activation and inhibition hematol. Col Clin North America 1990;4:1-26.

20. North American symptomatic carotid endarterectomy trial patients collaborators. Beneficial effect of carotid endarterectomy in symptomatic with high grade carotid stenosis. N Engl J Med 1991;325:445-53. 